By CLIFFORD B. CLAPP

\title{
Critique and Design on the Cost of Cataloging
}

Mr. Clapp is head of the catalog department, University of Pennsylvania Library, Philadelphia.

$\mathrm{T}$ HIS YEAR a call has been issued to reconsider cataloging. It has been a call so clear and insistent that it cannot be disregarded either by catalogers, or administrators of cataloging, or administrators of libraries. It concerns the theory or philosophy of cataloging, its efficiency, and even more its cost. In recent talks on the subject at the meetings of the American Library Association in Boston and Cambridge stress has been laid on the cost of cataloging. Both Mr. Metcalf ${ }^{1}$ and Mr. Osbor $n^{2}$ have issued a challenge to catalogers and administrators to remedy the increasingly difficult situation of mounting costs. $^{3}$ When, with their papers before us, we rehearse their analyses and appeals, we find them both taking a very sympathetic position in placing a joint responsibility on library administrator and cataloger and in appealing for more mutual understanding and more collaboration. ${ }^{1}$ Metcalf, Keyes D. "The Attitude of the Li-
brary Administrator toward Cataloging." Bulletin 35:P-48-51, Sept. 1941.

2 Osborn, Andrew D. The Crisis in Cataloging. 194I. Also in the Library Quarterly in:409-10, Oct. I94.

${ }_{8}^{4}$ I Since the present paper was written the experimental division on library cooperation of the Library of Congress has issued as its first bulletin Herbert $A$. Kellar's Memoranda on Library Cooperation, Sept. 194I, which contains an important section on the same situation and the related problems of cataloging arrears.

MARCH, 1942
At the same time there seems to be an implication that the difficulties are mainly the cataloger's problem, which the librarian must study and help her to solve. The feeling is probably pretty general that the major responsibility is the cataloger's. A somewhat different view is shown in Miss MacDonald's paper, ${ }^{4}$ which followed Mr. Metcalf's at Boston. It is evident that she expects the librarian to take more of the responsibility than merely to insist and discuss and agree, that she expects of him at least a full partnership in the question and probably more. Is not that implied when she says, "Librarians need to develop a positive attitude to the card catalog"? It is evident, I am sure, when, after pointing out the development of specialized collections and services she asks (and answers), "Who is primarily responsible for such increases? Certainly not the catalogers."

It is not fair nor wise to place much stress on the share of responsibility to be borne by librarian or catalog department administrator or any group in the personnel. Mr. Metcalf and Mr. Osborn agree that administrators and catalogers have grown too far apart. The present paper, written from the point of view of the manager of a catalog department, is an attempt to lay the basis for some remedial

4 MacDonald, M. Ruth. to the Administrator." A.L.A. Bulletin 35:58-59, Sept. I94I. 
action in the face of this situation. What is written here is no catholicon. It teems with disputable assertions. But it is in some respect representative of conditions and needs observed by the writer in various libraries and may afford to librarians and catalogers some suggestions for definite cooperation and improvement.

There is a tendency to think about cataloging in general terms and in bulk. Viewed in such general fashion there is really no such thing as the cost of cataloging. There is forgetfulness of the fact that the cataloging dollar, like the housewife's dollar, is a relative thing. There is some disregard of the professions of catalogers that they are responding to the demands of reference departments, the cost of whose service is more seldom questioned. If these things seem to show too little thinking about cataloging, some other things indicate one-sided thinking or insufficient basic knowledge about cataloging.

For example, there is a tendency to blame the complexity of catalog cards and the multiplicity of entries and of special catalogs for the entire sin of cataloging expense. Overelaboration of records is, of course, a feature of costliness, but it is not per se the prime offender. Its main significance is not, in this age of rules and of machines, that it is time-consuming but that it tends to disproportionately expensive organization and personnel.

Mr. Osborn devotes several pages to the theories and niceties of cataloging and related functions of catalog departments and only two to the organization of the department. But he perfectly appreciates the importance of the organization to problems of cost, for he says, "Organizational questions are equally pressing," and he indicates several of these questions.

\section{Place of Personnel}

The place of personnel in catalog department work is probably the hardest thing to discuss in library publications. Questions of personnel are vital elements in cataloging cost, and they present the most serious problems of both catalog department heads and librarians, or at least they ought to be so considered.

In a paper like the present one, no allinclusive design for catalog department economy could possibly be set up. But it seems very important to present something, and for the sake of emphasis I am offering my little something with the personal pronoun.

Mr. Osborn has suggested that the library administrator needs to know a good deal about cataloging from the inside, and that a prospective administrator might well spend a year as an intern in a good catalog department. Let me suggest as an alternative to this that an actual library administrator spend a month in a bad cataloging department, or at least in one where the cost is running too high. I think that if that were done a sort of pattern would form in his conception of his catalog department, which would embrace much more than the questions of cataloging codes, theories of cataloging, and multiplicity of records.

In some libraries he would find that costs suffer because of poor equipment, because of great distances between points within the scope of everyday activities, and because reference tools are lacking. Aside from such local conditions, first, he would criticize bad habits in administration, like neglecting to see things through, toleration of disorderliness, and use of caustic criticism. Next, he would observe inadequate cooperation by superiors and coordinate departments in furnishing in- 
formation or making decisions. Then he would notice improper assignment of duties, especially neglect of possibilities of using lower-priced people on some work. I think he would discover that there was want of a simple system of dealing with portions of the material coming for cataloging. I think he would criticize the department for its habit of applying maximum instead of minimum standards of treatment in classifying and cataloging and shelflisting and marking. Among his classifiers and catalogers he would see that there was failure to discriminate between the permanent and the temporary and between the pristine and the already indexed or described. He would find, if it were an old catalog department, an inadequate psychological reaction to the situation, by higher-priced people especially, shown by overmeticulousness in unimportant matters, inability to place reliance on others, unadaptiveness to new work or methods, and, finally, slowing down.

\section{Conditions Affecting Cost}

Such are some of the conditions affecting the cost of cataloging that would be found in some departments. It would be silly, of course, to infer any implication here that they are characteristic of all catalog departments or that all these conditions would prevail in one department.

A longer period in the catalog department would bring out some factors of larger scale and significance that dominate the work no matter what may be its personnel and organization. The first is the exceeding importance of machines of the right type and quantity, like typewriters, electric erasers, and book trucks, and, in some circumstances, mimeograph and pasting machines. The next is proper light and air and some degree of medical in- spection. Another is the planned flow of books into the department. Then there is the need for better budgeting of libraries and catalog departments.

It is a fact, strange as it may seem, that many cataloging chiefs are less bound by tradition and seemingly inexorable precedent than librarians and the heads of the public departments and less afraid of doing wrong than the principal members of their own staffs. Supposing that in the search for efficiency and reformation of costs such a catalog department head is sitting at a council table with the librarian or his deputy, with papers and plans giving a broad view of the department. A candid exposition would probably reveal three main things appearing as immovable as mountains: first, a well-developed organization on traditional lines; second, a high cataloging standard; and third, a practical disregard of the possibility of dispatching collections of books, papers, and costs on anything like a budgetary basis.

\section{Librarian Knows Functions}

The librarian would know the individual positions and salaries of the members of the catalog department, and he would know in a general way the functions they were performing, like classifying, shelflisting, filing, and so on, and the types of material they were handling, such as art, science, and education. Of course he would know their individualities and capabilities. It is doubtful whether he would know that card work was 25 per cent of cost, and administration 7 per cent, or that the work of a shelflister was one tenth or one twenty-fifth of the cost of cataloging.

In a library adding ten, twenty, or thirty thousand volumes a year and handling a considerable amount of special col- 
lection and departmental library work, together with cooperative work, films, maps, and the like, there are at least a dozen basic positions or functions in the cataloging service. From two to four of these may be combined into single positions.

In smaller libraries the functions of these positions exist but may be still further combined. For example, in a library handling six thousand volumes without much departmental library work the dozen places might be combined into about four. In a very large library the skeleton outline would be developed according to need by adding more persons in some positions, more catalogers, more typists, and so on. This is a standard organization, not necessarily the ideal one.

\section{Positions in Catalog Department}

These dozen positions are (I) superintendent, (2) distributor, (3) classifier, (4) general cataloger, (5) serials cataloger, (6) shelflister, (7) card secretary, (8) reviser, (9) card filer, (I0) typist, (II) book preparer, (I2) departmental library agent. The distributor receives books from half a dozen different sources and routes them to classifiers and catalogers, may interpose at any point in the routine to forward books, and is the natural follow-up agent for anything that is searched for or anything that is unduly delayed. Hers is a key position, which demands one of the most intelligent and well-balanced persons on the staff. Nevertheless, her salary rating will average five against a classifier's six or seven. The serials cataloger may catalog new serials and adjust old ones, but she must (if the position is a single one) devote most of her time to routine adding of volumes and parts. In salary she may rate as low as four, but, if there is a full-fledged serials division with two or more members, she may go as high as seven. The card secretary orders and receives printed cards, directs mimeograph work, and supervises the typists. In smaller departments her work may be combined with shelflisting, revision, filing, searching files, etc. The book preparer pastes and marks books. The departmental library agent forwards books to departmental libraries, receives books from them, visits them, advises their librarians and the officers of the department, sometimes does their filing, and in general acts as liaison agent with the main library. She has to be a person of tact and ability, but her rating is only three or four, unless she acts as classifier or cataloger for departments. The card filer, responsible only for filing in the public catalog, rates at three or four on the basis of her main work, and since she files only about half time she does other work of about the same grade. In a small library she may be responsible for other files. In a library with a depository Library of Congress catalog a separate filer is necessary. In the very large library the work of neither filing position can be handled by one person alone.

The ratings of which $I$ have spoken are salary ratings, based on a unit system in which a page is one unit. The ratings are those which it is necessary to give to the positions in order to obtain and keep competent people. They are as follows: (I) Superintendent, 7 to 14 ; (2) Distributor, 4 to 6 ; (3) Classifier, 5 to 8 ; (4) Cataloger, 4 to $7 ;(5)$ Serials cataloger, 4 to 7 ; (6) Shelflister, 3 to 5 ; (7) Card secretary, 3 to 4 ; (8) Reviser, 4 to 5 ; (9) Card filer, 3 to 4 ; ( 10 ) Typist, 2 to 3 ; (I I) Book preparer, 2 to 3 ; (I2) Departmental agent, 3 to 4 . 


\section{Minimum Requirements}

After a couple of combinations of positions, with a skeleton staff of ten, at the lowest ratings, the catalog department's minimum requirements will be just under forty; without such combinations, and with average ratings, the requirements will be between fifty-five and sixty. If the unit of rating is valued at $\$ 300$, the department must pay a minimum of about $\$ 12,000$ and a maximum of $\$ 18,000$, the latter at average and not maximum salaries, to carry on the twelve functions that have been detailed.

What can be obtained for this money?

Matching volumes cataloged against number of people in the department, calculations made on the basis of figures from several large university libraries show production ranging all the way from eight hundred to twenty-five hundred or three thousand volumes cataloged per year per person in the department. In the case of the eight hundred there is reason to think that the department employed quite a number of low-priced people, who gave either part-time or else low-degree service. In the case of the other extreme, twentyfive hundred or three thousand, I apprehend that everything went through the mill, foreign dissertations, multiple copies of textbooks, etc. When you try to match volumes cataloged against salaries of people in the departments, there are closer similarities between some libraries and greater discrepancies between some. Figures for several show cost per volume ranging from $85 \phi$ to $\$ 1.15$, and I hear sometimes of $65 \phi$ and $\$ 2$. I do not believe any reliance can be placed on anything but the most exact knowledge of conditions. The figures are practically worthless, except to suggest that what I call a skeleton staff of ten people paid rather poorly might catalog fifteen thousand volumes a year.

\section{Some Doing Less Work}

If that is the case, then some catalog departments are doing proportionately less work with a larger staff, or a higher-paid one, than if they had the skeleton staff. Bear in mind that I say proportionately. The work is intricate and positions are therefore mixed and therefore calculations are intricate and uncertain. But when cataloging staffs tend to produce less in proportion to their increase in size and in total salaries it means overbalancing somewhere. It may mean that the best-paid people, doing the higher-grade work, are doing comparatively less of it and that the work is in a manner of speaking too high grade. Some of it has to be refined but probably too much of it is too refined. The point, then, is that one method of reducing cost is to give a better balance to the staff, emphasizing possibly the middle grades. That may mean emphasizing the middle grades of work as well as of positions, and that probably means retreating somewhat from completeness and perfection.

The same conclusion must inevitably be reached if we read and reread the practical suggestions of $\mathrm{Mr}$. Metcalf and $\mathrm{Mr}$. Osborn. The same conclusion was reached longer ago by Ernest Cushing Richardson. Bibliographical cataloging has its place but numerically it is a minor one. Scholarship on the staff fosters respect for our classifiers and catalogers but scholarly and scientific research are not a main object of our work. I should be the last person to advocate lowering the standard of a major portion of our personnel. Bibliographers in a catalog department are necessary. There will be no quarrel 
with bibliographical cataloging of incunabula, early Americana, literary first editions, fine books, local items, and many undescribed rarities. The work on these must not be in the hands of second-rate people. But the place for most bibliographical work is in the keeping of certain types of special library, of custodians of special collections, and of private research. Full and well-nigh perfect cataloging is now standard, brought to that rating by the Library of Congress cards and by the A.L.A. rules. It is not the having of this perfection that is expensive, it is the perfect devotion to it, the single standard, the lapse from reason.

\section{Three Grades of Cataloging}

Mr. Osborn makes what is perhaps his most important practical suggestion when he calls for "three distinct and approved grades of cataloging" which would be followed "in the code" as well as "in many libraries." In connection with this we must not miss his statement that "standard cataloging," one of his three approved grades, "would be less detailed in many respects than the 1908 code or the Library of Congress formerly required."

If the cost of cataloging is to be lowered permanently a greater proportion of it must be done within the medium grades of salary requirement and a greater reliance must be placed on carefully developed lower grades. This has been exemplified in the development of preliminary cataloging at Harvard, a method adaptable in some degree at least to high-priced departments anywhere-prophecies of woe to the contrary notwithstanding.

Cataloging on the Library of Congress standard cannot be done except by a thoroughly trained or experienced professional staff. The great obstacle to acceptance of a medium grade of cataloging is that for many years now it has not been nationally standard. Therefore, the distribution of standard medium cards for a portion of the cataloging of a subject or type of material under the sponsorship of a national agency would definitely promote lower costs. The means are available: first, the outline of a code in Miss Mann's "local unit" card; second, the use of lower-cost preparation, perhaps on the lines of the Harvard system; third, the supplying of copy for current publications within certain agreed fields by ten or more libraries ; $;$ fourth, the production and distribution by one or more centers under the direction and authority of the Library of Congress of a considerable quantity of mimeographed instead of printed cards. ${ }^{6}$ Mimeographed cards, now being produced by the University of Pennsylvania and some other libraries, are at their best equal to or better than the best typewritten cards. By the combination of these stages the cataloging, production, distribution, and receipt of cards for a portion of the material cataloged could take place all within one week, at a lower cost than present Library of Congress work.

\section{Mechanics of Plan}

It would be impossible in a paper of this length to indicate the mechanics of such a plan, ${ }^{7}$ which is, after all, only one of the ways of standardizing medium cataloging-perhaps I should say restandardizing it. There are two or three ways of carrying out the project or of experimenting with it on a considerable scale. It is easy to understand the objections to a

\footnotetext{
5 Most of the libraries should be located in big cities and act as sponsors for cooperative cataloging in those metropolitan areas.

${ }_{6}$ Enabling the Library of Congress to print more cards for important works.

7 Kellar invites the discussion of such plans.
} 
plan like this on the part of catalogers disliking to see a retrogression in the beauty and legibility of even a portion of the cards, and on the part of librarians responsive to the demands of reference departments for the highest degree of inclusiveness of information. Nevertheless, if the single aim is economy, there is here required new understanding, willingness, and courage, and no little energy and tedious study.

Alteration of the organization of a catalog department has to come about gradually. In contemplating such alterations, happy may be the librarian who has arrears of material to be cataloged. ${ }^{8}$ It is the easier for him to make shifts of work without injustice to existing personnel. This is not intended to justify arrears; but in streamlining the department, to use Mr. Osborn's term, the librarian with arrears has the greater resources. He can budget these resources over, say, a threeyear period. After providing for the books purchased for immediate use he can determine the time required and the cost of preparation of the rest of the books, including the collections on hand and the average accessions of gifts. He can force the cataloging, or in some cases the simple classifying and indexing, of, say, one third of the material in one year, within the stipulated cost, by whatever method is required to accomplish it. This is important: by whatever method is required to accomplish it. He can receive periodically, or at the end of the year, a statement of arrears within the plan, with the reasons therefor, of unforeseen accessions and of special unforeseen work, and of the cost of carrying on the plan on the same or a revised basis.

${ }^{8}$ See the figures on arrears in Kellar's Memoranda.

\section{Budgetary Control}

Handling library accessions in this way is the identical twin of budgetary procedure, concerning which John H. MacDonald has written, ${ }^{9}$ "Budgetary control assumes a genuine desire on the part of the entire organization, from the president to the office boy, to keep as close to the previously charted course as possible, to accept responsibility for doing so, to check actual performance against the plans, and in every other respect to use the budget as a real road map to reach the previously established goal."

But if the library has no arrears-and this would be a happy situation, too-does not the plan of dispatching collections on a budgetary basis suggest the idea of some temporary cataloging or even listing, pending the grouping of lots or masses of like material which can be most economically done by groups? Since the question is how to economize, the hypothetical diminishing of the catalog's service and all the predicted difficulties of reclaiming books for completion of work cannot be allowed to prevent the consideration of such a policy for at least a portion of the acquisitions or accumulations.

In the present year there is much mooting of cataloging questions. On account of the issuance of the tentative second edition of the A.L.A. code, there will be enough discussion to satisfy the most enthusiastic or serious devotees of technical excellence. The time should not pass without a very serious, if not enthusiastic, discussion of the technique involved in reform of catalog department expense, and discussion should not end without some sort of national or general action.

9 MacDonald, John H. Practical Budget Procedure, New York, Prentice-Hall, Inc., I939, p. 2. 